\title{
Analysis of Apparel's Pattern Grading on Basic Collar Contour
}

\author{
Li-na Cui ${ }^{1, \text { a }}$ \\ ${ }^{1}$ Deparment of Arts and Design, Quanzhou Normal University, Quanzhou, P.R. China; \\ aemail: cuilina-cui@163.com
}

\section{Keywords: Apparel Pattern; Basic Collar Contour; Pattern Grading; Stepping Data}

\begin{abstract}
Before we make pattern grading of apparel, we have to master the changing law of the human body. In this research, we withdrew human measurements through the advanced non-touched 3D body scanner, and then utilized SPSS software to analyze the data gathered, and then through geometric method we obtained the law of basic collar contour changing with body size. Furthermore, the stepping data of apparel basic collar contour in pattern grading was concluded.
\end{abstract}

\section{Introduction}

Apparel pattern grading is the production of the development of apparel industry. As living standard improves, people's requirement towards garment fitting is more and more increasing. At the same time, according to the requirements of garment batch production, the same style of the garment has to adapt to different body shape of people for wearing. This requires the same style of clothing must be produced in accordance with many specifications and different size series. Patterns used for garment industry are the main technical material and also the foundation of garment cutting in mass production, and in order to ensure the sample size is accurate, at the same time the work is efficient, when making the pattern design, we always first develop one or two standard patterns, then have this pattern zoom in and out, so all patterns with different sizes we need are made. This process is called pattern grading. The technology of pattern grading is an important element in apparel manufacturing; it not only affects garment enterprise's productivity, but also determines the apparel fitting and appearance [1].

\section{The Status of Pattern Grading in Garment Industry}

The graphical form of apparel pattern grading is not simply graphics displacement, but through system processing according to the stepping data of different apparel detailed specifications, and after that we can get pattern grading graphic which meets body fitting requirement. The determination of apparel detailed specifications has to take "National apparel size standard of the People's Republic of China "as the basis, "The National standard "is completed on the basis of scientific investigation to human body, and concluded by using mathematical statistics and analysis methods. "The National standard" shows us the stepping data of some major parts of human body. Table 1 shows "GB/T1335.1-1997" National Men's apparel size standard, the values and stepping numbers of control sizes of 5.4A body shape. The values are the basic and important reference data when making pattern grading [2].

We can see easily from the table 1, what we can obtain from the "National apparel size standard" are the data of different steps of human basic control parts and stepping data, But the sizes of apparel pattern depend on dimensions of different body detail parts commonly. So when we confront the problem of pattern grading to the detail parts, such as shoulder slope, collar neck and armhole etc, we have no data for reference. We can only depend on our experience to set and adjust the stepping data and pattern. Therefore this will lead to lacking of regulatory and larger randomness on pattern grading. This research mainly focuses on the pattern grading on shoulder slope. 
Tab. 1 GB/T1335.1-1997" National Men's apparel size 5.4A" (unit:cm)

\begin{tabular}{cccccccccc}
\hline parts & \multicolumn{1}{c}{ data } \\
\hline height & 155 & 160 & 165 & 170 & 175 & 180 & 185 & 5 \\
cervical height & 133.0 & 137.0 & 141.0 & 145.0 & 149.0 & 153.0 & 157.0 & 4 \\
cervical height (sitting) & 60.5 & 62.5 & 64.5 & 66.5 & 68.5 & 70.5 & 72.5 & 2 \\
arm length & 51.0 & 52.5 & 54 & 55.5 & 57 & 58.5 & 60 & 1.5 \\
waist height & 93.5 & 96.5 & 99.5 & 102.5 & 105.5 & 108.5 & 111.5 & 3 \\
chest circumference & 72 & 76 & 80 & 84 & 88 & 92 & 96 & 100 & 4 \\
neck circumference & 32.8 & 33.8 & 34.8 & 35.8 & 36.8 & 37.8 & 38.8 & 39.8 & 1 \\
shoulder across & 38.8 & 40.0 & 41.2 & 42.4 & 43.6 & 44.8 & 46 & 47.2 & 1.2 \\
waist circumference & 58 & 62 & 66 & 70 & 74 & 78 & 82 & 86 & 4 \\
hip circumference & 77.2 & 80.4 & 83.6 & 86.8 & 90.0 & 93.2 & 96.4 & 99.6 & 3.2 \\
\hline
\end{tabular}

\section{Analysis on Pattern Grading of Basic Collar Contour}

The basic collar contour is also called the primary neck line, it forms neck circumference from human body's back neck point (BNP) to shoulder neck point (SNP) then to front neck point (FNP), and it is the foundation of collar pattern design. Any collar pattern must first draw the basic collar contour, and then changes are made in pattern according to style and sculpt [3].

Basic collar contour is a very important part on apparel structure, and as basic collar contour close to the head, is the center of attention, which directly affects the fitness, comfortable and beauty of clothing. At the same time, apparel neck line is directly related to the type of collar structure shape and is provided the overall style of harmony and performance, affects the shoulder shape, physical function, but also will impact the shape of collar, cuff, and whole body. So the grading of clothing collar has important influence on clothing's final overall effect.

In this research, we compare a dozen of apparel manufacturing enterprises' references document of apparel grading and finally find, different manufacturing enterprises have different methods and data on pattern grading of basic collar contour. The method most enterprises use is keeping the grading data the same on front half neck width, back half neck width, while grading data on front neck-drop is greater than back neck-drop. Some other enterprises keeping the grading data the same on front half neck width, back half neck width and front neck-drop, while no grading on back half neck width. And still few enterprises keep neck curve of all sizes parallel.

As we know, apparel pattern is restricted by the shape of human body, that only follow the body shape's changing laws will the apparel pattern be practical. Therefore, apparel pattern grading should be consistent with human body, but also combine with the graphics and clothing styles' changing rule, so the garment pattern grading will make the perfect unity between human body and graphical scale and style. The grading of basic collar contour should according to the law which body neck line changing with the body size. Therefore, this study carries on relevant research such as body measurement experiment related to this question in order to find out this changing law.

\section{Experiment on Anthropometric Measurement of 3D}

\section{Experiment Equipment}

This experiment utilizes non-touched 3D human body laser scanner made by German TecMath Corporation to carry on human body data acquisition, this scanner can scan the $2.1 \mathrm{~m}$ high region in 8 10 seconds, the resolution may reach $5 \mathrm{~mm}$, measuring accuracy for $\pm 2 \mathrm{~mm}$.

\section{Experiment Scope}

The survey scope is 300 aged from 19 26 years old male university students.

\section{The Establishment of Body Measurement Project}

Referring to the correlative measurements of collar pattern design, this research withdraws data 
of 8 measurements (two human bodies foundation measurement: height and chest circumference; 10 neck related detail sizes, symmetric part measure one side only), the detail items can be seen in Fig1.

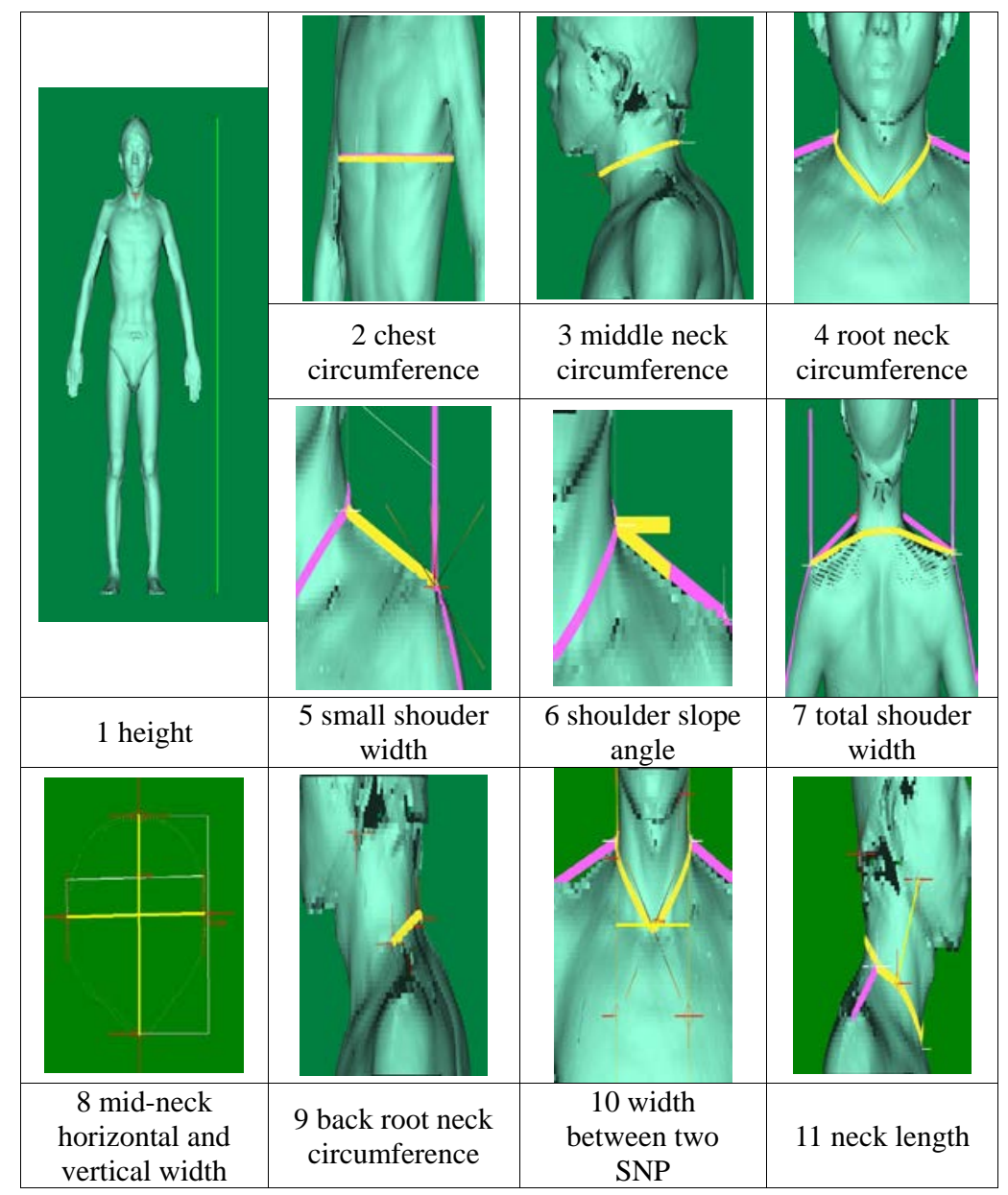

Fig. 1 Digital human measured position

\section{The Relationship Between Pattern Parts of Basic Collar Contour and Human Body Foundation Measurements}

\section{Cluster Analysis on Measurements.}

Cluster analysis is also called group analysis. It is a common mathematical method which study on how to make reasonable classification to objective things.

There are many items can reflect body neck's characteristics, and in order to find out the representative items which can reflect body neck's most important characteristics from so many items, and enable them to serve to apparel MTM,it's necessary to carry on cluster analysis to these measured items. This research uses SPSS statistics software $\mathrm{R}$ type clustering to the variables[4]. 
Table 2 Cluster agglomeration schedule

Agglomeration Schedule

\begin{tabular}{|l|r|r|r|r|r|r|}
\hline \multirow{3}{*}{ Stage } & \multicolumn{3}{|c|}{ Cluster Combined } & \multicolumn{2}{|c|}{$\begin{array}{c}\text { Stage Cluster First } \\
\text { Appears }\end{array}$} \\
\cline { 2 - 3 } \cline { 5 - 6 } & Cluster 1 & Cluster 2 & Coefficients & Cluster 1 & Cluster 2 & Next Stage \\
\hline 1 & 1 & 3 & .819 & 0 & 0 & 5 \\
2 & 5 & 10 & .819 & 0 & 0 & 5 \\
3 & 6 & 7 & .665 & 0 & 0 & 7 \\
4 & 2 & 4 & .657 & 0 & 0 & 6 \\
5 & 1 & 5 & .649 & 1 & 2 & 6 \\
6 & 1 & 2 & .542 & 5 & 4 & 7 \\
7 & 1 & 6 & .323 & 6 & 3 & 8 \\
8 & 1 & 8 & .046 & 7 & 0 & 9 \\
9 & 1 & 9 & -.019 & 8 & 0 & 0 \\
\hline
\end{tabular}

After classification, 10 neck related detail measurements are divided into 5 categories, according to body measurement which the basic neckline design need for, we withdraw 3 characteristic indexes, and they are root neck circumference, back root neck circumference, width between two SNP.

\section{The Regression Relationship Between Basic Neckline Structural Feature Index and Body Foundation Measurements}

Through the SPSS statistical software regression analysis, we obtain the mathematical regression equation between neck characteristic indices and body foundation measurements , the regression relationship is important basis of clothing collar pattern design .Chest denotes by B, and height by $\mathrm{H}[5]$.

Tab. 3 One and two element regression equation between the basic neckline's characteristic index and chest circumference /height

\begin{tabular}{|l|l|c|c|c|}
\hline measurements & \multicolumn{1}{|c|}{$\begin{array}{c}\text { two element regression } \\
\text { equation }\end{array}$} & $\begin{array}{c}\text { Determinant } \\
\text { coefficient } \\
\mathrm{R}^{2}\end{array}$ & $\begin{array}{c}\text { one element } \\
\text { regression } \\
\text { equation }\end{array}$ & $\begin{array}{c}\text { Determinant } \\
\text { coefficient } \\
\mathrm{R}^{2}\end{array}$ \\
\hline $\begin{array}{l}\text { Root neck } \\
\text { circumference (Z1) }\end{array}$ & $\begin{array}{l}0.223 \\
* \mathrm{~B}+0.0047 * \mathrm{H}+22.436\end{array}$ & 0.317 & $0.223^{*} \mathrm{~B}+23.26$ & 0.318 \\
\hline $\begin{array}{l}\text { Back root neck } \\
\text { circumference (Z2) }\end{array}$ & $0.071 * \mathrm{~B}+0.087^{*} \mathrm{H}+7.323$ & 0.292 & $0.071^{*} \mathrm{~B}+8.512$ & 0.293 \\
\hline $\begin{array}{l}\text { width between two } \\
\text { SNP (Z3) }\end{array}$ & $0.066^{*} \mathrm{~B}+0.0004 * \mathrm{H}+7.26$ & 0.251 & $0.065 * \mathrm{~B}+7.312$ & 0.251 \\
\hline $\begin{array}{l}\text { Front root neck } \\
\text { circumference } \\
\text { (Z1-Z2) }\end{array}$ & $0.15^{*} \mathrm{~B}-0.0043^{*} \mathrm{H}+15.342$ & 0.192 & $0.15 * \mathrm{~B}+14.215$ & 0.193 \\
\hline
\end{tabular}

\section{The Calculation Equation of Pattern Parts on Basic Collar Contour}

The key problem of basic collar contour's pattern design is the determination of neck width and neck-drop's size, the neck width in patter's counterpart is width between two SNP, and the neck-drop in pattern and the body parts are difficult to correspond, but it can be calculated by geometric computation.

Shown as Fig. 2, AB is the position of half neck-width in the pattern of basic collar contour, AC is neck-drop, and DE is deepness of neck line arc. Their lengths are separately expressed as a, b, and $r$. The size "r" decided by the human body neck root's curve, but regarding different sizes of neck, the difference is unobvious. This article referred to the making of neck line of Japanese block 
as well as to consult the experienced pattern makers, and finally determined front neck line $\mathrm{r} 1=2.5 \mathrm{~cm}$, back neck line $\mathrm{r} 2=0.6 \mathrm{~cm}$.

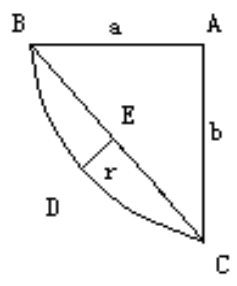

Fig.2 collar line

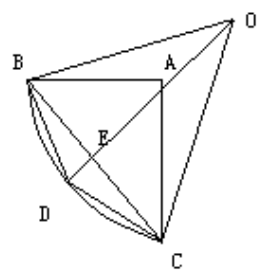

Fig.3 collar line with auxiliary line

Shown as Fig. 3, point $\mathrm{O}$ is the centre of Arc BDC; suppose its radius is $\mathrm{R}$, then we can conclude, $\mathrm{OB}=\mathrm{R}, \mathrm{OE}=\mathrm{R}-\mathrm{r}$; and suppose Line segment $\mathrm{BC}=2 \mathrm{c}, \mathrm{Arc} \mathrm{BDC}=\mathrm{m}$, and we can conclude following equation from geometry relation:

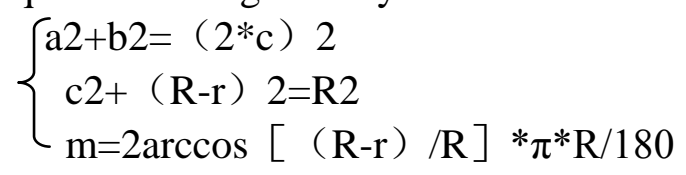

Respectively calculates front half neck-width b1and back half neck-width b2 from each individual sample in this research, and calculates the regression relationship with basic human measurements and basic neck measurement root neck circumference (chest circumference is expressed as B and root neck circumference as $\mathrm{N}$ ), and then we obtain computing formulas of front and back half neck-width and front and back neck-drop in basic collar contour pattern design as follow.

Table 4 Computing formulas (units: $\mathrm{cm}$ )

\begin{tabular}{llll}
\hline Front half neck width & Back half neck width & Front neck-drop & Back neck-drop \\
\hline $0.038 * \mathrm{~B}+3.6$ & $0.038 * \mathrm{~B}+3.6$ & $0.120 * \mathrm{~B}-1.8$ & $0.015 * \mathrm{~B}-0.2$ \\
\hline
\end{tabular}

\section{The Determination of Basic Collar Contour's Pattern Grading Data}

We can know from the above table, the grading data for pattern parts of basic collar contour can be concluded by below equation.

Stepping data of Front half neck width $=0.038 *$ Stepping data of chest circumference;

Stepping data of back half neck width $=0.038 *$ Stepping data of chest circumference;

Stepping data of front neck-drop $=0.12 *$ Stepping data of chest circumference;

Stepping data of back neck-drop $=0.015 *$ Stepping data of chest circumference.

While in the current national standard number 5.4 size series, the stepping data for chest circumference is $4 \mathrm{~cm}$, so we can obtain the grading data of basic collar contour in the table below through the calculation, the data sheet will provides more accurate reference data for clothing enterprises to grading the apparel neck pattern.

Tab. 5 Grading data of basic collar contour

\begin{tabular}{llll}
\hline Front half neck width & Back half neck width & Front neck-drop & Back neck-drop \\
\hline 0.15 & 0.15 & 0.4 & 0.06 \\
\hline
\end{tabular}

\section{Conclusion}

The grading of apparel pattern is a key technology and an important section in garment industrial production process. The grading of apparel pattern should be on the basis of the understanding the shape and specifications of human body, and mastering the changing law of body shape. In this research we withdraw human measurements through the advanced non-touched 3D body scanner, then utilize SPSS software to analyze the data gathered, and then obtain the law of shoulder slope changing with body size. Furthermore, the stepping data of shoulder slope in pattern grading is 
concluded. And this conclusion may be good reference for people who undertake the grading of apparel pattern.

\section{References}

[1]Pan Bo. Industrial apparel pattern design. Beijing: China textile press, 2000:18-35

[2]The National Standard GB/T1335.1-1997 apparel size-men,State Bureau of Technical Supervision,1997-11-13,7-8.

[3]Dai Hong. Apparel size standard system and application .Beijing: press of china textile, 2001.10-11.

[4]Su Jinming. Application and development guide of statistical software SPSS 12.0 for windows .Beijing: press of electronic industry, 2004.315-321.

[5] Lu Wudi, SPSS for Windows statistical analysis. Beijing:Publishing House of Electronics Industry, 2002:141 